\title{
O sertão amansado
}

\author{
Candice Vidal e Souza \\ Doutora em Antropologia Social \\ (Museu Nacional/Universidade Federal do Rio de Janeiro) \\ Professora da Pontifícia Universidade Católica de Minas Gerais \\ Belo Horizonte, MG, Brasil \\ candice.vidal@yahoo.com.br
}

\begin{abstract}
Resumo A proposta do artigo é analisar o livro O sertão carioca, de Armando Magalhães Corrêa, publicado em 1936. Trata-se de um registro de observação direta da paisagem e da conversa com os moradores, combinando-se com os desenhos do autor. Interessado no registro da geografia física, da fauna e da flora típicas das áreas rurais compreendidas na planície de Jacarepaguá, o autor enfatiza os ofícios e modos de viver existentes nesses sertões além da Barra da Tijuca. A descrição das características físicas, sociais e dos tipos humanos encontrados nas viagens do autor por regiões próximas ao Rio de Janeiro, então capital da República, revela um sertão perto da civilização, porém desconhecido. Cabe-nos pensar sobre as características da narrativa de um sertão próximo, curioso mas inofensivo à nacionalidade, se comparado com os sertões bravios e longínquos, espaços privilegiados no olhar geográfico sobre o Brasil.
\end{abstract}

Palavras-chave: representações da nação, sertão carioca, Magalhães Corrêa, alteridades geográficas, pensamento social.

\section{Introdução}

No ano dois mil, quando os nossos melhores romances já não tiverem mais leitores, alguns estudiosos subirão as escadas das bibliotecas para folhear O sertão carioca. (Do prefácio de Edgar Roquette-Pinto)

$\mathrm{F}$ altava pouco para o ano 2000 quando encontrei o livro O sertão carioca, de Armando Magalhães Corrêa, nas prateleiras de um sebo no Rio de Janeiro. Em minhas leituras de inúmeros textos conhecidos e esquecidos sobre os sertões brasileiros, nunca tinha visto referência a essa obra publicada em 1936. Encantada com a minha descoberta, comprei o livro e o guardei por vários anos. Certa vez, perguntei ao professor Luiz de Castro Faria se ele conhecia o livro. Respondeu-me que sim e que o autor trabalhara no Museu Nacional. O seu tom me parecera dizer que só eu não conhecia ainda esse livro e de que não seria uma obra de qualidades extraordinárias.

Ao propor uma leitura de $O$ sertão carioca que colocasse esse texto em contraste com outros registros intelectuais sobre sertões brasileiros, deparei-me com o fato de que o livro já tinha sido explorado em trabalhos recentes (Sarmento, 1998; Franco e Drummond, 2005). Portanto, apresento um livro que não é incógnito. A proposta é reunir o seu autor entre aqueles pensadores que se dedicaram a descrever sertões e a refletir sobre esses lugares na formação do Brasil, empreendendo também uma análise das avaliações e interpretações que essa revelação de sertão carioca gerou em sua época. Neste caso, haveria certas ideias em torno de sertões mais típicos, associados a espaços ermos, vazios e situados Brasil adentro que se projetam quando do comentário sobre esse sertão tão próximo do mar e da cidade representativa da civilização litorânea, o Rio de Janeiro, capital. 
O sertão, alteridade geográfica e social, assentado por poderosa tradição narrativa do pensamento social brasileiro, está presente no olhar do autor, viajante pelos caminhos além da Barra da Tijuca, e de seus contemporâneos leitores. No entanto, argumento aqui, em todas as impressões geradas pelo encontro com o sertão carioca, sua natureza e sua gente, vê-se que esse texto resulta em um discurso sobre um sertão sim, porém, sem o impacto que a reflexão diante da alteridade mais radical produz no pensamento sobre a nacionalidade e seus outros internos.

Vejamos então qual a diferença relatada por Magalhães Corrêa, posto que, ao usar a expressão "sertão" para qualificar essa região próxima à cidade, ele está a enunciar o estranhamento diante de ambientes naturais, práticas de trabalho e modos de vida. Mas que sentimentos e reflexões sobre os brasileiros aí encontrados e o Brasil são produzidos pelo contato com alteridades "vizinhas"? Intelectuais brasileiros que falaram sobre o sertão têm como referentes lugares e pessoas brasileiros; a condição da conacionalidade que envolve a todos produz a ambivalência característica das narrativas sobre sertão, que alternam percepções positivas e negativas sobre as condições sertanejas.

O sertão carioca, curioso mas inofensivo, amansado pela proximidade do litoral e pela inexistência do deserto (vazio de civilização e de Estado) em seu entorno, leva a todos que observamos os sertões et- nográficos e os sertões imaginados pelos intelectuais a nos perguntarmos sobre as variantes dos modos de significar e interpretar as descontinuidades internas ao espaço nacional.

\section{O sertão carioca: o livro e seu autor}

O sertão carioca foi publicado em 1936 sob os auspícios do Instituto Histórico e Geográfico Brasileiro, pela Imprensa Nacional. Antes, seu conteúdo saíra publicado na forma de artigos no jornal carioca Correio da Manhã, entre 1931 e 1932. Como informam José Luiz Franco e José Augusto Drummond (2005), o diretor da revista do IHGB, Ramiz Galvão, foi incentivado por Ricardo Palma e Edgar Roquette-Pinto a reunir na forma de livro as reportagens com "informações primárias recolhidas no trabalho de campo do próprio autor, na forma de extensas e assíduas caminhadas por trilhas, estradas, fazendas, areais, praias, lagoas, aquedutos, barragens e pontes" (Franco e Drummond, 2005, p. 1037). A delimitação indicada pelo autor para a região percorrida e registrada por suas anotações e desenhos em bico-de-pena abre o seu texto: ${ }^{1}$

A vasta zona da terra carioca, denominada planície de Jacarepaguá (vale dos jacarés), compreendida entre

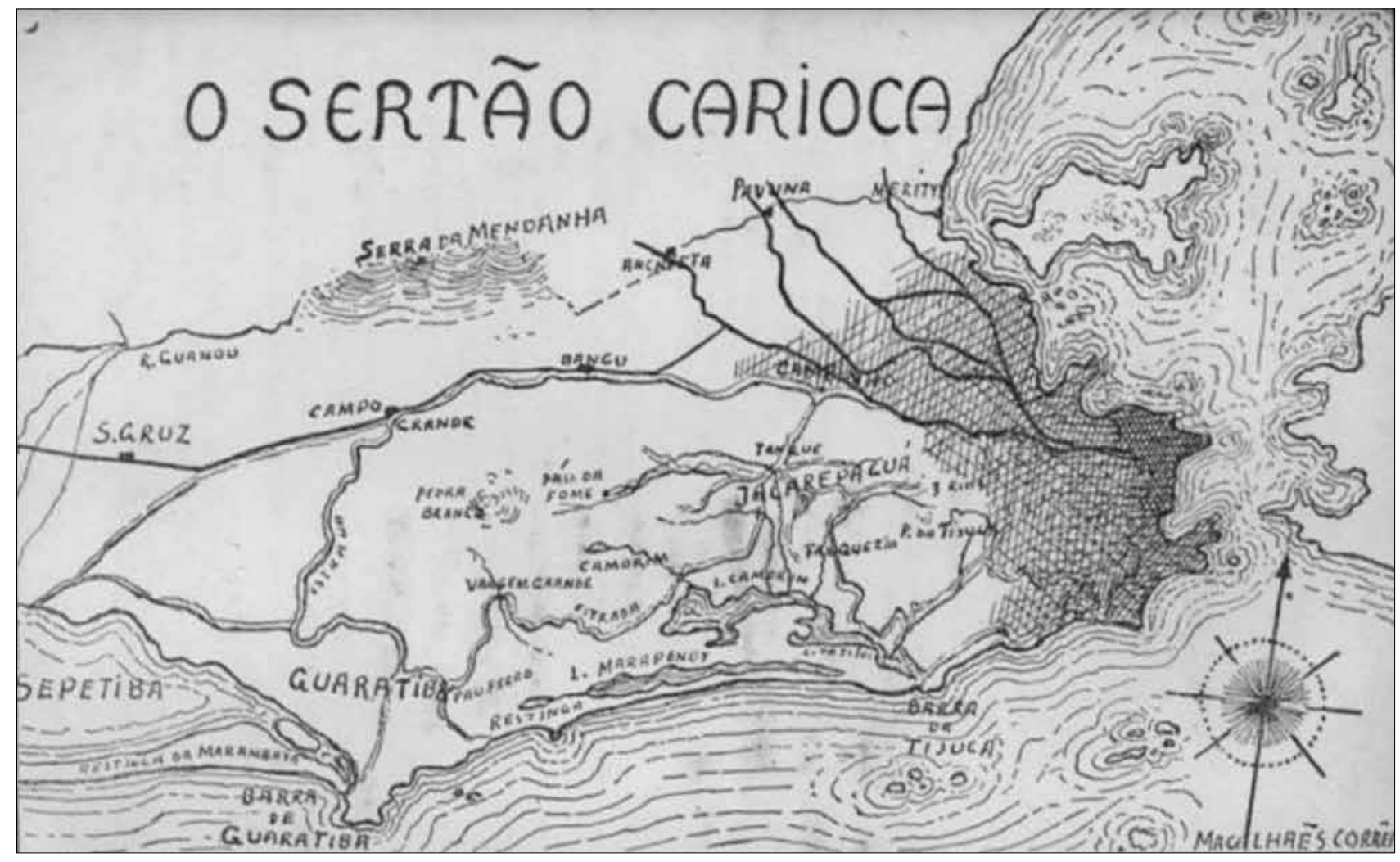

Mapa da região denominada “sertão carioca” (Magalhães Corrêa, 1936, p. 273) 
os maciços da Tijuca e da Pedra Branca, é constituída pelos vales dos tributários das lagoas da Tijuca e Camorim; por essas lagoas e a de Marapendy (mar limpo), na restinga de Itapeba (lage), pelos Campos de Sernambetiba e pela Restinga de Jacarepaguá, com suas dunas, a qual é o anteparo do Oceano Atlântico. Começa no Campinho, com o nome de Marangá (vale da batalha) entre este e o morro do Valqueire (vale de pau-ferro), na altitude de 40 metros do nível do mar. No Tanque, a 14 quilômetros do Campinho, dilata-se consideravelmente, chegando a ter 6 quilômetros de largura. Deste ponto, vai progressivamente aumentando, até encontrar o Oceano, onde alcança a sua maior largura, formada pela bacia hidrográfica das lagoas da Tijuca, Camorim, Marapendy e Campo de Sernampetiba. Aí da Barra da Tijuca (morro da Juatinga - Juá branco) até a base do Morro das Piabas, alcança 23 quilômetros de extensão, mais ou menos. Do Campinho ao Oceano, a extensão é de 15 quilômetros; o terreno vai em declive suave, seco, até as Estradas da Tijuca, do Camorim, Vargem Grande e Piabas; daí ao litoral, pode-se dizer, é quase em sua totalidade alagadiço, com as lagoas, os campos (Sernambetiba), as matas Tropófilas e as Halófilas. Essa grande planície tem por assim dizer a forma topográfica de um funil, cuja área é calculada em 160.000.000 de metros quadrados. (Magalhães Corrêa, 1936, p. 23)

O mapeamento preciso de um sertão demarcável é um aspecto inusitado dessa descrição de um lugar chamado de sertão, pois a imprecisão geográfica e a fluidez dos limites divisores que separariam o sertão do não sertão são características apontadas pelos estudos sobre o sertão etnográfico e o sertão dos intelectuais (ver Sena, 1986; Vidal e Souza, 1997; Moraes, 2002-2003). A condição do sertão como atributo simbólico conferido a lugares de fronteiras incertas é esclarecida por Antonio Carlos Robert Moraes: "Na verdade, o sertão não é um lugar, mas uma condição atribuída a variados e diferenciados lugares. Trata-se de um símbolo imposto - em certos contextos históricos - a determinadas condições locacionais, que acaba por atuar como um qualificativo local básico no processo de sua valoração. Enfim, o sertão não é uma materialidade da superfície terrestre, mas uma realidade simbólica: uma ideologia geográfica" (Moraes, 2002-2003, p. 13).

Esse é o território percorrido. Segundo o autor,

foi esse pedaço do Distrito Federal que muito me impressionou e por isso pensei relatá-lo em pálidas no- tas, apanhadas em excursões, visto não ter sido objeto de observação dos nossos estudiosos. Aí encontrei uma população laboriosa, bem brasileira, cujos usos e costumes me levaram à denominação de Sertão Carioca. (Magalhães Corrêa, 1936, p. 23-24)

Os registros detalhados da constituição geológica, aspectos da fauna e da vegetação dos vários lugares visitados, assim como a descrição das espécies vegetais e animais conhecidas e trabalhadas por pescadores, machadeiros, carvoeiros, esteireiras, cesteiros, tamanqueiros, cabeiros, oleiros, caçadores e bananeiros, faz-nos lembrar os cuidados de um observador cientista, próximo do cientista naturalista que desvendava as regiões interiores das colônias analisado por Pratt (1992, especialmente capítulo 2). Segundo a autora, "na segunda metade do século dezoito, fosse ou não uma expedição prioritariamente científica ou o viajante um cientista, a história natural tinha um papel nela. Coleta de espécies, a construção de coleções, a nomeação de novas espécies, o reconhecimento daquelas já conhecidas, tornaram-se temas padrão em viagens e livros de viagem" (Pratt, 1992, p. 27). ${ }^{2}$

As formas de trabalho e as técnicas narradas detalhadamente por Magalhães Corrêa confirmam a preocupação com a acurácia descritiva que existe em relação ao hábitat e também se estende aos aspectos humanos (sociais e físicos). As pessoas com quem ele conversou, que lhe relataram suas atividades e suas condições de vida, têm seu nome informado. Muitos homens são referidos por nome, idade, nome e origem dos pais, estado civil, cor e altura. O propósito desse expediente parece ser a confirmação de que o autor fala de um lugar "bem brasileiro". Como ele diz, "o pessoal que vive nesse sertão, longe da civilização, é todo ele brasileiro" (Magalhães Corrêa, 1936, p. 77). Algumas vezes o autor nota a presença de "estrangeiros", descritos sem simpatia quando sua presença é de exploradores do trabalho dos sertanejos cariocas (cf. Magalhães Corrêa, 1936, p. 90).

Ao longo do texto, Magalhães Corrêa faz várias observações cujo teor indica a compreensão do sertão como lugar onde pessoas e costumes são brasileiros. Sobre o povoado de Camorim (situado a $15 \mathrm{~km}$ de Cascadura), onde se localiza uma colônia de pescadores, diz:

Nesse ambiente bem brasileiro, e um tanto isolado, impera ainda a alma pura de nossos caboclos, tudo lembra o que é nosso, os tipos e costumes. Os pescadores são brasileiros, predominando entre eles cariocas e fluminenses, bronzeados pelo sol, rígidos de

2 No original: "in the second half of the eighteenth century, whether or not an expedition was primarily scientific, or the traveler a scientist, natural history played a part in it. Specimen gathering, the building up of collections, the naming of new species, the recognition of known ones, became standard themes in travel and travel books" (Pratt, 1992, p. 27). 
caráter, patriotas, audaciosos em sua técnica, conhecedores de todos os detalhes de sua profissão e da fauna marítima-fluvial, aliando-se qualidades extraordinárias, físicas e morais, conquistadas à custa de sua árdua profissão. (Magalhães Corrêa, 1936, p. 60-61)

Para chegar a esses redutos de brasilidade, partindo-se da capital, é preciso dispor-se a viajar. O deslocamento espacial deve ser acompanhado de disposição de aventura e exploração. De outro modo, tal empreendimento resultará em uma viagem em torno do conhecido. Magalhães Corrêa convida seu leitor a encontrar em Jacarepaguá brasilidades sertanejas da seguinte forma:

Jacarepaguá, com sua vida própria, num ambiente bem brasileiro, apresenta seus habitantes com usos e costumes da nossa gente sertaneja.

Querem conhecê-la? Infiltrem-se por suas serras, planícies, restingas, alagados, lagoas e rios, onde sua flora é exuberante e a fauna abundante, mas não pelas belíssimas estradas de rodagem, porque aí nada perceberão; hão de passar sem compreender e sentir a alma dessa gente leal, hospitaleira, de têmpera férrea, que aí trabalha. (Magalhães Corrêa, 1936, p. 205)

Percorrer os caminhos, observar a natureza e conversar com os moradores foram os recursos empregados pelo autor para encontrar o sertão próximo e desconhecido da gente leitora e refinada da cidade. Os primeiros registros foram tomados na condição de visitante domingueiro aos lugares por onde excursionava: Jacarepaguá, Barra da Tijuca e Guaratiba e as encostas do maciço da Pedra Branca (Franco e Drummond, 2005 , p. 1037). Dado seu encantamento, o autor comprou um sítio em Jacarepaguá, onde passava fins de semana. Depois, decide morar com sua família no local.

Em razão dessa aproximação existencial com o ambiente descrito, a "retórica da paisagem" existente em O sertão carioca deve ser abordada tendo-se em conta as observações de Caio Maciel de que, "como construção interpretativa, a paisagem é mediadora do entrecruzamento das experiências individual e coletiva de um espaço ao mesmo tempo material e simbólico, sedimentado pela historicidade. Decorre daí a importância dos aspectos argumentativos contidos nas descrições de paisagens como fios condutores para uma geografia imaginativa profundamente enraizada nas qualidades do meio físico e na biografia do autor que vivencia e/ou imagina o espaço, bem como do contexto histórico em que as obras foram escritas" (Maciel, 2009, p. 117). Como argumento adiante, trata-se também de um reconhecimento (e de fazerse reconhecer) de tais qualidades do meio físico e social, posto que tal geografia imaginativa é partilhada por outros observadores de paisagens pelo Brasil.
Armando Magalhães Corrêa nasceu e morreu no Rio de Janeiro (1889-1944). Desenvolveu variadas atividades ao longo da vida, tendo sido "escultor, desenhista, professor e escritor" (Franco e Drummond, 2005 , p. 1036). Fez curso de escultura na Escola Nacional de Belas Artes e foi artista premiado. Colaborou com o jornal carioca Correio da Manhã por meio de textos e desenhos em bico-de-pena. Suas habilidades artísticas se combinaram com os interesses de naturalista. Trabalhou como conservador na Seção de História Natural do Museu Nacional do Rio de Janeiro. Como informam Franco e Drummond,

aprendeu [...] a desenhar plantas e animais, habilidade muito valorizada pelos estudiosos da botânica e da zoologia do seu tempo, quando eram limitadas as possibilidades de registro fotográfico de espécimes raros e paisagens agrestes. Os seus conhecimentos de história natural e a sua capacidade de produzir imagens sobre a natureza o transformaram em professor do Museu Nacional e da Escola de Belas Artes do Rio de Janeiro. (Franco e Drummond, 2005, p. 1037)

No livro O sertão carioca, estão presentes o conhecimento e a curiosidade do naturalista e a representação hábil da natureza e dos tipos humanos em desenhos entremeados aos textos. Entretanto, um de seus ilustres prefaciadores não deixa de notar a precariedade estilística do trabalho. Edgar Roquette-Pinto comenta que

o pitoresco com que o artista soube descrever os diferentes e individualizados tipos profissionais do Sertão Carioca faz perdoar o desleixo do estilo. Direi mais; a maneira simples, desataviada, apressada, descuidada mesmo, com que Magalhães Corrêa foi traçando as suas notas, deu ao volume um sabor de fruta agreste, colhida na árvore, ainda quente do sol. (RoquettePinto, in Magalhães Corrêa, 1936, p. 9)

A avidez pelo registro imediato desse mundo em descoberta deve ter sido responsável pelo texto apressado, sem qualidades literárias. Mais interessante é a cobrança de Roquette-Pinto de que o apuro estilístico deve ser preocupação de quem escreve relatórios de observação de paisagens naturais e sociais. A escrita ensaística é uma marca distintiva do pensamento social brasileiro. Desse modo, a forma com que se expressam as ideias sobre o Brasil constitui um aspecto relevante para compreender a longevidade dessas narrativas.

Magalhães Corrêa parecia estar mais preocupado com a indicação precisa dos caminhos percorridos, como se estivesse ensinando ao leitor como ele mesmo poderia chegar aos locais citados. Ele ainda se ocupa em nomear as pessoas com quem conversa, 
além das companhias que teve em algumas excursões especiais. O passeio pelo Pontal de Sernambetiba foi conduzido por J. W. Finch, "americano de nascença, mas brasileiro de coração, como diz ele" (Magalhães Corrêa, 1936, p. 150). Eis o comentário do autor:

Pela gentileza daquele senhor fizemos o circuito a cavalo, que durou duas horas, do Pontal à lagoa de Marapendy, atravessando o rio das Taxas, os campos das Flexas na Restinga de Itapeba, 'habitat' florestal da Goethea, base do Morro do Rangel, e novamente o Pontal. Nessa excursão tomaram parte os professores Roquette-Pinto e A. J. Sampaio, os naturalistas Brade e Bertha Lutz, e o Sr. J.W. Finch. Acompanhounos a pé o guia encarregado dos cavalos. (Magalhães Corrêa, 1936, p. 150)

Edgar Roquette-Pinto tomou parte de outra excursão com o autor. Dessa vez, porém, as visões da natureza do sertão úmido do Rio de Janeiro foram substituídas pelo encontro do abandono. No capítulo "Estradas e sítios", o autor menciona aspectos da vida dos moradores constatados em sua experiência. O primeiro parágrafo é uma denúncia: "Infelizmente o saneamento rural não existe para a zona de Camorim a Vargem Grande; o Centro de Saúde está localizado no Campinho, e o médico que deveria ao menos passar, uma vez por semana, em socorro dos pobres trabalhadores e seus filhos doentes, aí não aparece" (Magalhães Corrêa, 1936, p. 189). Conta então o episódio a que assistiu:

Em excursão à caixa d'água de Camorim, quando em companhia do Professor Roquette-Pinto e seu filho Paulo, encontrei o filho do encarregado da mesma num estado lastimável, o qual, examinado por Paulo Roquette, quinto anista de medicina, constatou formidável esplenomegalia [hipertrofia do baço], grande anemia e febre intermitente, e estava sendo tratado com chá de pitanga, não podendo o pobre pai levá-lo ao Campinho, por estar sozinho em seu posto e lhe faltarem os recursos para a passagem do auto-ônibus, única condução, o que forneceu aquele professor. Soube ultimamente que a infeliz criancinha morrera... (Magalhães Corrêa, 1936, p. 189)

Os exemplos de falta de assistência à saúde e nas escolas aparecem nos comentários de Magalhães Corrêa. Reclama das poucas escolas, da inadequação do ensino à realidade local, como no trecho a seguir:

A população escolar dessa zona é obrigada a percorrer quilômetros ao sol e à chuva, sendo a distância entre elas de oito quilômetros. Se os pais quiserem que seus filhos aprendam a ler, com o regime atual, quando nenhum material é fornecido aos nossos guris, terão a multa de $50 \$ 000$ a $200 \$ 000$ se estes faltarem mais de três vezes! Isto prova que os nossos dirigentes da Instrução Pública, quando não são leigos, são verdadeiros provincianos, não conhecem os usos e costumes e a psicologia dessa população rural. O programa de ensino é o mesmo do centro da capital da República! (Magalhães Corrêa, 1936, p. 114)

As notas de desalento em função do abandono da instrução pública aparecem ainda em relação a Jacarepaguá. Há escolas de difícil acesso ou ainda sem material escolar básico (cf. Magalhães Corrêa, 1936, p. 206).

Nesse sertão carioca o autor percebe a exploração do trabalho da gente simples e a pouca paga que recebem por seu trabalho ou produtos fabricados. $\mathrm{Na}$ derrubada da madeira, por exemplo, o empreiteiro recebe $5 \$ 000$ por tora de tabebuia, que será vendida por até $70 \$ 000$ a serrarias e fábricas. Sobre um manobreiro da represa de Camorim diz que vive

em uma pequena casa de sopapo, coberta de sapê, à beira da estrada, com três filhinhos e a esposa. $\mathrm{O}$ pobre homem é obrigado a manobrar todas as comportas das caixas e represas nos momentos de perigo, num temporal, velar pelo bom andamento, conservação e limpeza, noite e dia, sem um momento de folga, ganhando duzentos e quatro mil réis! (Magalhães Corrêa, 1936, p. 49)

O caminhante que escreveu tais observações, a meu ver, não pode ser julgado como um observador que idealiza o que vê. O sertão carioca de Magalhães Corrêa não é apenas natureza e recantos encantadores ou modos de vida graciosamente brasileiros. Há traços fortes de descaso, isolamento, precariedade das condições de vida. Discordo da leitura de Carlos Eduardo Sarmento, que ressalta "a representação do sertão idílico” por Magalhães Corrêa. Espero que os trechos antes citados sejam suficientes para pôr em dúvida análises como a de que "um dos primeiros cuidados tomados pelo autor é o da qualificação de um homem de características rousseaunianas nas periferias da capital federal brasileira em plena década de 1930. O retrato do sertanejo é basicamente desprovido de mazelas" (Sarmento, 1998, p. 10-11).

Em certos momentos, o texto revela profunda simpatia e encantamento do autor com os aspectos naturais e certos costumes encontrados nesse interior próximo ao mar e à cidade grande. Como no relato sobre o sítio de Luiz Ribeiro Filho em Vargem Grande:

A vida aí é agradável; passei o dia de Santo Antônio em companhia da minha família e da do meu amigo Luiz Ribeiro: durante o dia passeios a cavalo aos sítios próximos; a criançada divertiu-se no rio; à tarde, 
jogou-se peteca e assim se passou o dia. À noite, a tradicional fogueira, soltaram-se fogos e não faltaram o melado, o aipim, a batata, o milho e a canjica. A criançada, louca de alegria, saltava a fogueira, comia, dançava e gritava. [...] Balões atravessam o espaço e, ao longe, foguetes espoucavam, numa noite poética de luar; de vez em quando, chegavam sons de violões e cânticos sertanejos, dos sitiantes mais distantes, fazendo recordar os tempos passados... (Magalhães Corrêa, 1936, p. 192) $)^{3}$

O mundo descrito não é visto como paraíso, posto que Magalhães Corrêa enxerga sinais de degradação da natureza, com danos causados pelos próprios moradores. Como notam José Luiz Franco e José Augusto Drummond,

Corrêa, embora admirasse os sertanejos peri-urbanos que entrevistava e cujas atividades descrevia tão bem, não os poupava da sua parcela de responsabilidade pelas alterações ambientais denunciadas. Para ele, na maior parte das vezes, era a própria população residente que a devastava, apesar de necessitar da terra e dos seus recursos, sem ter consciência do prejuízo que causava. (Franco e Drummond, 2005, p. 1040)

Em minha leitura de O sertão carioca concordo com a opinião desses dois autores de que "Corrêa não idealizava a vida dura dos sertanejos cariocas" (Franco e Drummond, 2005, p. 1041), sobretudo porque seu olhar e seu envolvimento com o lugar não são de um visitante de passagem. Desse modo, não vejo fundamento no texto para afirmações peremptórias presentes na análise de Carlos Eduardo Sarmento, como a de que "o cenário construído por Corrêa parece pertencer a uma das páginas da prosa romântica oitocentista. Maravilhado com o espaço que o cerca o narrador contempla signos alheios ao seu cotidiano" (Sarmento, 1998, p. 10).

A percepção de nuances no cenário percorrido cessa no livro apenas quando o autor se refere às práticas religiosas identificadas no sertão carioca. Vemos aí que o narrador de fato se distancia daquilo que descreve e carrega de desvalor outras práticas religiosas que não aquelas "doutrinas mais elevadas, como o cristianismo” (Magalhães Corrêa, 1936, p. 206). O leitor atento desse capítulo fica incerto quanto à existência empírica de todas as práticas, objetos, rituais e crenças citados no território demarcado como sertão carioca. Parece-me que o autor pesquisou tudo que estava ao seu alcance para falar de jujuísmo, orixás e macumba, motivado pela clara aversão a esses assuntos, mais que pela necessidade de esclarecer sobre realidades diretamente presenciadas em sua convivência no lugar. Como diz sobre o jujuísmo [fetichismo], "aqui no Distrito Federal, africanos ou seus descendentes praticam-no com muita reserva, sendo mesmo raro no sertão carioca" (Magalhães Corrêa, 1936, p. 208). Não fica clara a relação entre o que escreveu e o que viu.

Os comentários sobre rituais de iniciação no candomblé têm tom depreciativo: "A esse sinal, principia a medonha bacanal e a evocação do santo pelos cantos. O noviciado, já sobejamente sugestionado e entusiasmado pelo fanatismo, entra numa dança infernal, acenando e gesticulando horrivelmente" (Magalhães Corrêa, 1936, p. 213). Sobre Exu diz que é um "espírito malévolo" e Yemanjá, "a verdadeira personificação da prostituta" (Magalhães Corrêa, 1936, p. 209). A opinião do autor sobre a "macumba" é de que trata-se da "religião dos malandros cariocas, da classe inculta, cujo fervor está em razão direta de seu atraso, rito espiritualista, misto de catolicismo, fetichismo africano e superstição indígena, verdadeira adaptação louca do jujuísmo praticado no candomblé” (Magalhães Corrêa, 1936, p. 217).

Entretanto, há uma rápida passagem ao final dos comentários sobre as religiões afro-brasileiras que aponta para alguma observação feita em campo. Magalhães Corrêa informa que "contribuiu para estas notas um pai-de-santo, o velho Felipe, de raça negra, e quando dele me despedi assim falou 'cala a boca mia fio! Que isso é segredo, oio vê e boca cala"” (Magalhães Corrêa, 1936, p. 221). Não sabemos com precisão em que pontos esse pai-de-santo ensinou ao visitante nem se ele mora em terras do sertão carioca. Como o autor lista cinco obras de referência sobre religião, não se sabe o que foi resultado de pesquisa bibliográfica ou do encontro com Felipe. Quanto ao pedido de segredo, deve ter sido desobedecido nessas revelações de observador que recrimina o visto e o ouvido.

3 Esse mesmo trecho é comentado, com outro ânimo interpretativo, em Sarmento (1998, p. 9-10). Antes da transcrição do trecho citado, observa que "A representação construída pelo texto torna-se mais evidente através da simbolização de um homem que existe enquanto entidade que se realiza e se satisfaz na interação com a natureza. Daí emerge uma visão idealizada desta relação e do próprio homem sertanejo, figuração esta central para o desenvolvimento de todo o texto. A imagem mágica deste sertão carioca pode ser melhor sintetizada por uma passagem que expressa a forma de inserção do narrador/observador participante, estupefato com o meio idílico/tradicional. " Depois da citação de Magalhães Corrêa, segue-se o comentário: "O cenário construído por Corrêa parece pertencer a uma das páginas da prosa romântica oitocentista. Maravilhado com o espaço que o cerca o narrador contempla signos alheios ao seu cotidiano. [...] Esta nostalgia de um passado imaginado contribui para a qualificação do sertão como espaço idílico vinculado diretamente à noção de uma áurea outrora perdida." 


\section{Sertão bravio e sertão manso: seus intérpretes}

O livro O sertão carioca compõe-se de prefácios e comentários, os quais são reveladores de representações sobre o sertão como categoria de interpretação da nacionalidade brasileira. A surpresa diante de um lugar o qual se aceita ser denominado sertão é seguida de comentários que buscam justificar também sua distinção em relação a um verdadeiro sertão, este mais bravio e afastado que a região descrita por $\mathrm{Ma}-$ galhães Corrêa.

Um elogio comum ao autor cita sua capacidade de ver e descrever o que não se imaginava existir tão perto. O diretor do Instituto Histórico e Geográfico Brasileiro, B. F. Ramiz Galvão, comenta no primeiro prefácio:

Viajantes e cientistas estrangeiros de grande valor [...] se votaram à descrição da natureza dos nossos sertões longínquos e aos costumes dos nossos bravos sertanejos. Faltava-nos um pesquisador idôneo para tratar desta zona vizinha da capital brasileira. (Galvão, in Magalhães Corrêa, 1936, p. 3)

A descoberta do sertão próximo foi celebrada na resenha de Ricardo Palma, publicada no Diário Carioca em 20 de setembro de 1932. Diz em suas notas:

Pouca gente, hoje, escreve sobre as coisas do Rio de Janeiro. E os poucos que escrevem, se limitam à história. Mas ultimamente um desses escritores [...] resolveu, como Fernão Paes, 'entrar pelo sertão'. Sim, embora o carioca da Avenida, do posto 4, dos chás e cinemas chics fique espantado, existe, nesta sua maravilhosa terra, um 'sertão', como na Amazônia, em Mato Grosso, em Goiás, em Minas, na Bahia. Embora menos bravio...Sim, senhores, o Rio tem o seu sertão. E que sertão maravilhoso, a cujas verdes portas se pode bater de automóvel, em escassas horas, por ótimas estradas. (Palma, in Magalhães Corrêa, 1936, p. 11)

Os textos que abrem o registro de Magalhães Corrêa confirmam que há uma diferença de modos de vida e um estado de natureza que merecem o reconhecimento de sertão, contudo, mais manso, menos primitivo, presença que não ameaça. Em contraste com outros sertões que estão lá no Brasil distante do Rio de Janeiro, esses sim que os leitores têm em mente, o lugar encontrado por Magalhães Corrêa é pitoresco, onde se vive em relativo isolamento da "civilização" e da modernidade.

A caracterização desse sertão ameno, de onde se pode ir e vir de um mundo a outro sem riscos e aventuras, é clara nas imagens usadas pelo prefaciador
Edgar Roquette-Pinto (a quem o autor dedica o livro), ele mesmo um expedicionário pelos sertões do oeste e também integrante de algumas excursões com o autor ao “'campo' da Guanabara”. Escreve ele que

a duas horas do Palácio Monroe ainda hoje fazem farinha de mandioca, no 'sertão de Guaratiba', empregando o tipity, igualmente aos que em 1500 serviam para espremer a massa de many. Quer, porventura, isso dizer que a nossa terra ficou ancorada no atraso daquele século? Nunca. O tipity é companheiro da luz elétrica, do rádio, do automóvel... (RoquettePinto, in Magalhães Corrêa, 1936, p. 8)

O sertão carioca não é visto como ameaça ou resistência ao centro civilizador. O que há de curioso aí é a preservação de formas de vida tidas por autenticamente brasileiras, algumas heranças do período colonial. Em comparação com outros sertões que se configuram melhor como alteridades exemplares dentro da nação, a região sertaneja do Rio de Janeiro, tal como relatada no livro, gera curiosidade e preocupação quanto à necessidade de evitar sua degradação natural.

Esse sertão não se presta à posição de margem ou alteridade subalterna na configuração da nação. No entanto, o vigor das referências assentadas entre nossos intelectuais sobre verdadeiros sertões mostrase nas comparações e imediatas distinções apontadas entre o lugar próximo e as terras Brasil adentro. Carlos Eduardo Sarmento observou a presença do sertão canônico construído por Euclides da Cunha no reconhecimento feito por Magalhães Corrêa de um sertão carioca. O comentador nota que a visão do sertão carioca se distingue daquela apresentada em $O s$ sertões, "ao erigir uma visão idílica do objeto e ao não reconhecê-lo como algo fundamentalmente distinto, como radical alteridade" (Sarmento, 1998, p. 7-8).

As ressalvas à interpretação de que Magalhães Corrêa enxerga o sertão carioca como lugar idílico foram pontuadas. Contudo, considero acertada a compreensão de que nem autor nem comentadores da época reconheceram alteridade plena nesse território ou nas pessoas que o habitam. Em outra ocasião, argumentei que nem mesmo Euclides da Cunha viu o sertão de Canudos e as pessoas de lá como completos outros (Vidal e Souza, 1997).

Nesse ponto, devemos expor aqui o problema interpretativo da figura do narrador. Qual o seu lugar no cenário que descreve? Tenho procurado investigar os vínculos entre o autor de registros sobre o Brasil e os locais narrados, seja ele ensaísta, literato, naturalista ou repórter, para que se articulem as representações dos lugares, costumes e pessoas nomeados como sertanejos com a experiência da viagem do observador e as condições sociais da sua observação. De modo 
geral, porém, o fato de falar de coisas e pessoas dentro do Brasil produz certos compromissos entre narrador e lugar descrito, pois que ele é um brasileiro descobrindo outros. Não há distanciamento pleno aqui, pois os valores e categorias de interpretação nacionais estão em ação.

Cabe pensar também se a relação puramente intelectual (sem a experiência da viagem e da convivência) como o sertão narrado no pensamento social molda certas avaliações também normativas, ainda que se queiram críticas. Um analista imaginário cuja inexperiência etnográfica ou distância existencial com esses universos designados sertanejos parece reduzir a especificidade das interações concretas e dos registros delas resultantes à reprodução de esquemas canônicos de ver o sertão. Insisto aqui em apontar a ambiguidade valorativa dos modos de narrar o sertão (espaço e sociedade) quando escritores e comentadores são brasileiros. Falta-nos, contudo, iluminar o lugar de fala do comentador de textos e de representações várias sobre o sertão, da mesma maneira que precisamos conhecer mais sobre os muitos narradores (externos e internos) que os lugares do sertão mobilizam.

\section{Espaços da diferença: a etnografia dos sertões e a antropologia dos intelectuais que pensam o sertão}

Uma leitura extensa dos discursos sobre o sertão e sobre sertões particulares deixa-nos o registro desses lugares e comunidades como cenários onde se marca uma diferença. Para se dizer sobre o sertão ou sobre sertões, o narrador recorre à comparação e à diferenciação com lugares e modos de viver que se vê como não sertão. A localização e a descrição do que é e do que não é sertão consiste no ato de nomear diferenças e de tentar impô-las como princípios de divisão e classificação do espaço nacional. Trata-se aqui de apontar os efeitos performativos da atividade de inúmeros intelectuais que escrevem sobre paisagens sociais e físicas ditas sertanejas. O que pretendo considerar mais detidamente é a condição existencial daquele que narra o sertão: é um intelectual do lugar que se ocupa de registrar histórias e tipos humanos de sua aldeia por meio do texto ensaístico, memorialístico ou literário (ver Rodrigues, 2006; Jacinto, 2006); ou um intelectual de passagem, em visita às terras do interior, mas que vive na grande cidade e mantém a estranheza, "a sensação de não estar de todo" descrita por Flora Süssekind (1990), mesmo que se demore no lugar e por ele simpatize.

Aqueles que têm se dedicado aos textos que narram o sertão em planos mais ou menos empíricos acabam por distinguir o escritor como de dentro, que vê de perto; de fora, que vê de perto; de fora, que vê de longe (numa apropriação livre de ideias de José Guilherme Cantor Magnani, 2002). Nosso autor, Armando Magalhães Corrêa, pode ser definido como um observador de fora, que vê de perto. No entanto, seu trajeto em busca do sertão é de curta distância, pois dá por achado o sertão carioca tão perto da capital. Ele se distingue do narrador exemplar que acredita que a brasilidade seria encontrada em gentes e paisagens do interior profundo do Brasil, bem mais longe da vida metropolitana. O sertão carioca não resulta de viagens ao centro do país, aos cafundós, ao cerne da nacionalidade (cf. Süssekind, 1990, p. 14), mas lá o autor encontra marcas de brasilidade autêntica. É esse encontro com o Brasil definido como original que justifica e legitima entre os leitores de Magalhães Corrêa a denominação de sertão para a região identificada no mapa.

Vê-se nesse texto o vínculo da categoria sertão com a representação da nação de modo independente dos sentidos de distância, selvageria, vazio, mundo pastoril, movimento e errância. Esse sertão permanece, mas na condição domesticada, ${ }^{4}$ como "bom sertão", inofensivo, admirável, bem diferente dos sertões plenamente outros (Costa, 2003; Vidal e Souza, 2003). Qualquer diferença incômoda é rechaçada pelo autor, como nos assuntos religiosos que mencionei antes.

Para aqueles antropólogos que viajam a lugares que se autodenominam sertão ou que são ditos assim por outrem cabe revelar e compreender os modos de autorrepresentação das pessoas que vivem nos sertões percorridos por tantos intelectuais ou observadores eruditos. Acredito que ainda reste muito a fazer no plano da etnografia dos sertões e dos sertanejos, principalmente se fizermos coincidir as regiões do trabalho etnográfico com as regiões demarcadas por textos eruditos. Como pontuei em relação aos sujeitos alvo da reportagem jornalística pelo Brasil interior (Vidal e Souza, 2003), há muito a ser feito na percepção de como se veem aqueles com lugar subalterno na representação do Brasil, condição que se dá porque são sempre descritos e falados por outros; e mais: como eles percebem a relação com os visitantes ilustres e os registros produzidos sobre eles. A questão a investigar é se o sertão é um território que "se constitua em significante de identidade (pessoal ou coletiva), instrumento nos processos ativos de identificação e representação da identidade em um sentido que 
poderíamos chamar de militante". Assim, a etnografia com os sujeitos habitantes dos sertões haverá de confirmar se "o território é o cenário de reconhecimento; as paisagens (geográficas e humanas) que o formam são os emblemas em que nos reconhecemos e exigimos realidade e materialidade ante nossos próprios olhos e aos olhos dos outros" (Segato, 2007, p. 73). ${ }^{5}$

5 No original: "se constituya em significante de identidad (personal o colectiva), instrumento em los procesos activos de identificación y representación de la identidad en un sentido que podríamos llamar de militante." Assim, a etnografia com os sujeitos habitantes dos sertões haverá de confirmar se "el territorio es el escenario del reconocimiento; los paisajes (geográficos y humanos) que lo forman son los emblemas en que nos reconocemos y cobramos realidad y materialidad ante nuestros propios ojos y a los ojos de los otros" (Segato, 2007, p. 73).

\section{Referências}

ATLAS DAS REPRESENTAÇÕES LITERÁRIAS DE REGIÕES BRASILEIRAS. Sertões brasileiros, v. 2. Rio de Janeiro: IBGE, Coordenação de Geografia, 2009.

COSTA, João Batista de Almeida. Mineiros e baianeiros: englobamento, exclusão e resistência. 2003. Tese (Doutorado em Antropologia) - Universidade de Brasília, Brasília, 2003.

FRANCO, José Luiz de Andrade; DRUMMOND, José Augusto. Armando Magalhães Corrêa: gente e natureza de um sertão quase metropolitano. História, Ciências, Saúde-Manguinhos, v. 12, n. 3, p. 1033-1059, set./dez. 2005. JACINTO, Andrea Borghi Moreira. Margens escritas: versões da capital antes de Brasília. XXV REUNIÃO BRASILEIRA DE ANTROPOLOGIA, Goiânia, 2006. (GT 50 Sertão: sentidos e re-sentidos).

MACIEL, Caio Augusto Amorim. Sertões Nordestinos: Literatura e retórica da paisagem. In: ATLAS DAS REPRESENTAÇÕES LITERÁRIAS DE REGIÕES BRASILEIRAS. Sertões brasileiros, v. 2. Rio de Janeiro: IBGE, Coordenação de Geografia, 2009.

MAGALHÃES CORRÊA, Armando. O sertão carioca. Rio de Janeiro: Imprensa Nacional, 1936.

MAGNANI, José Guilherme Cantor. De perto e de dentro: notas para uma etnografia urbana. Revista Brasileira de Ciências Sociais, v. 17, n. 49, p. 11-29, jun. 2002.

MORAES, Antonio Carlos Robert. O sertão: um "outro” geográfico. Terra Brasilis, n. 4-5 (Território), p. 11-23, 2002-2003.

PECHINCHA, Mônica Thereza Soares. O Brasil no discurso da antropologia nacional. Goiânia: Cânone Editorial, 2006.
PIMENTEL, Sidney Valadares. O chão é o limite. A festa do peão de boiadeiro e a domesticação do sertão. Goiânia: Ed. da UFG, 1997.

PRATT, Mary Louise. Imperial eyes: travel writing and transculturation. London: Routledge, 1992.

RODRIGUES, Cintya Maria Costa. A região da aldeia: os pressupostos geográfico-espaciais da literatura goiana e a construção do Sudoeste de Goiás. In: XXV REUNIÃO BRASILEIRA DE ANTROPOLOGIA, Goiânia, 2006. (GT 50 Sertão: sentidos e re-sentidos).

SAID, Edward W. Orientalismo. O Oriente como invenção do Ocidente. São Paulo: Companhia das Letras, 1990.

SARMENTO, Carlos Eduardo. Pelas veredas da capital: Magalhães Corrêa e a invenção formal do sertão carioca. Rio de Janeiro: CPDOC, 1998.

SEGATO, Rita Laura. La nación y sus otros. Raza, etnicidad y diversidad religiosa em tiempos de políticas de la identidad. Buenos Aires: Prometeo Libros, 2007.

SENA, Custódia Selma. A categoria sertão: um exercício de imaginação antropológica. Brasília: PPGAS/UnB, 1986. (Mimeografado).

SÜSSEKIND, Flora. O Brasil não é longe daqui. São Paulo: Companhia das Letras, 1990.

VIDAL E SOUZA, Candice. A pátria geográfica: sertão e litoral no pensamento social brasileiro. Goiânia: Ed. da UFG, 1997.

VIDAL E SOUZA, Candice. Repórteres, reportagem e construção da nação no jornalismo brasileiro. 2003. Tese (Doutorado) - PPGAS/Museu Nacional/UFRJ, Rio de Janeiro, 2003. 


\title{
The tamed "sertão"
}

\begin{abstract}
The purpose of this article is to analyze the book O sertão carioca, by Armando Magalhães Corrêa, published in 1936. This book is an account of the direct observation of the landscape and conversation with dwellers, combined with the illustrations by the author. Interested in the register of the physical geographic features, fauna and flora of the rural areas in the lowland of Jacarepaguá, the author emphasizes the crafts and lifestyles of the people living in those sertões beyond Barra da Tijuca. His description of the physical and social characteristics and the human types found in his journeys through areas close to Rio de Janeiro, the capital of the Republic at the time, discloses a sertão that was at the same time unknown and yet so close to the town. Our role is to reflect on the characteristics of the narrative of a sertão that is close by, curious and at the same time harmless to nationality, if compared to the untamed and far-off sertões, which are privileged spaces to the geographic eyes of Brazil.
\end{abstract}

Key words: representation of the nation, "sertão carioca", Magalhães Corrêa, geographic alterities, social thinking.

\section{El Interior amansado}

\section{Resumen}

La propuesta del presente artículo es analizar la obra: O sertão carioca, de Armando Magalhães Corrêa, publicada en 1936. El libro es un registro de la observación directa del paisaje y de la conversación con los habitantes, combinado con los dibujos del autor. Interesado en catalogar la geografía física, la fauna y la flora típicas de las zonas rurales, ubicadas en la llanura de "Jacarepaguá", el autor hace hincapié en los oficios y en los modos de vivir existentes en el interior; más allá de la "Barra da Tijuca". La descripción de las características físicas, sociales y de los tipos humanos encontrados en los viajes del autor por las zonas cercanas a la ciudad de "Rio de Janeiro", en aquel entonces capital de la República, revela una región cerca de la civilización, pero, desconocida. Nuestra tarea es pensar sobre las características de la narrativa respeto a un área cercana, curiosa, pero inofensiva a la nacionalidad, en comparación a las regiones bravías y lejanas, espacios privilegiados bajo la mirada geográfica del Brasil.

Palabras-clave: representaciones de la nación, "sertão carioca”, Magalhães Corrêa, diferencias geográficas, pensamiento social.

Data de recebimento do artigo: 30/4/2010

Data de aprovação do artigo: 28/5/2010 